\title{
Claude Sumner and the Quest for an Ethiopian Philosophy
}

\author{
Fasil Merawi* $^{*}$
}

\begin{abstract}
African philosophy emerged out of the rationality debates and the need to affirm the existence of a unique African intellectual tradition that primarily reflects on the legacies of colonialism. Such a debate also centered on whether there is a unique philosophical tradition rooted on African traditional practices. In such a context, Ethiopian philosophy represents a unique approach in defying the colonial bias which is founded on the idea that philosophy is exclusively a western mode of thinking. It is also unique in being available among others in a written form which is absent in other philosophical traditions in Africa. In this paper, I will develop a critical exposition of Sumner's studies into the written, oral and sapiential sources of Ethiopian philosophy. I will discuss the contributions of Claude Sumner in light of questioning Eurocentric bias that undermined the existence of non-western philosophies, escaping the charge of ethno-philosophy, and situating Ethiopian philosophy on different modalities of Ethiopian experience. To attain such an undertaking, Sumner's investigations on Ethiopian philosophy and their major contributions to the attempt to introduce a unique philosophical tradition in Ethiopia will be discussed. Through a discussion of Sumner's works on Ethiopian philosophy, this paper attempts to situate the place of Ethiopian philosophy within the need to reflect on our existential predicaments. I will start my discussion by situating the forces that motivated Sumner's pursuits, and also elaborating on Sumner's explorations into the classical, oral and written sources of Ethiopian philosophy.
\end{abstract}

Keywords: Wisdom Literature, Philosophy, Sagacity, Narratives DOI: https://dx.doi.org/10.4314/ejossah.v15i1.3

* Lecturer, Department of Philosophy, Addis Ababa University, email: fasil.merawi@aau.edu.et, Tel: +251911990423, P.O. Box 1176/ Addis Ababa.

This work is licensed to the publisher under the Creative Commons Attribution-NonCommercialNoDerivs License. 


\section{Introduction}

Contemporary discussions in Ethiopian philosophy are directly influenced by the works of the Canadian philosopher Claude Sumner. Sumner devoted most of his life to studying the different dimensions of Ethiopian philosophy and wisdom. He produced volumes of books and numerous articles that demonstrated the existence of philosophy in Ethiopia and its varying manifestations. Following the works of Sumner on Ethiopian philosophy, one could identify three major modalities of Ethiopian philosophy. These constitute written philosophy, traditional oral wisdom found in proverbs and narratives and finally foreign philosophical wisdom that is synthesized and creatively adapted to the Ethiopian context. In this paper, I will discuss the contributions of Sumner in light of questioning Eurocentric bias that undermined the existence of non-western philosophies, escaping the charge of ethno-philosophy, and situating Ethiopian philosophy on different modalities of Ethiopian experience. Sumner's investigations of Ethiopian philosophy and their major contributions in Ethiopian philosophy will be discussed. The forces that motivated Sumner's pursuits and his explorations into classical and written sources of Ethiopian philosophy also emerge as major areas of analysis.

\section{Situating Ethiopian Philosophy in the Rationality Debates on African Philosophy}

Philosophically speaking, the existence of an indigenous philosophy reflecting on the fundamental questions of knowledge and born out of the local is questionable. Prominent African philosophers like Paulin Hountoundji maintain that African philosophy needs to retain a universal and objective dimension. Others like Odera Oruka on the contrary contend that there is a need to demonstrate the vitality of African local wisdom and teachings to the development of an African philosophical tradition. Based on such an argument the fate of African philosophy is bound with our historical horizons and modalities of existence. Whereas the universalist position claims that all philosophy as a rational exercise is global in its nature, the historicists emphasize the local, cultural and relative experience ${ }^{1}$.

\footnotetext{
${ }^{1}$ The universalist and historicist positions in philosophy are expressed largely in terms of the debate between objectivism and relativism. Universalists argue that human knowledge is objective, universal and goes beyond spatio-temporal locations, whereas relativists argue that the role of culture, communal values, geography, history and preferences of the subject are clearly witnessed in the quest for knowledge.
} 
Consequently, one should ask, "Is the nature of philosophy purely speculative, practical, or both?" (Medina, 1992, p. 373). What further complicates the issue is the fact that whereas culture is necessarily bound to a temporal location, the philosophical quest always contemplates the universal.

The conception of indigenous philosophy in Africa is mostly narrowly conceived as a situated form of knowledge limited by space and time. Thus, one asks how independent indigenous knowledge is from culture and local values. Furthermore, indigenous philosophy in Africa is part of a critique of colonialism where the revival of indigenous knowledge is seen as the foundation of uniqueness, freedom and emancipation. Thus, "the debate over the role of indigeneity in African philosophy is part of the larger postcolonial discourse" (Masolo, 2003, p. 22). For Masolo, resisting the attempt to confine indigenous philosophy to the local, all philosophy including the indigenous one should be founded on our experience, interaction with others and the rational accounts of the human condition. Just like the debate on African philosophy, the issue of whether Ethiopian philosophy exists is seen as a way of challenging the Eurocentric paradigm which saw only Europe as the locus of human culture and civilization.

For Teodros Kiros, any analysis of the role of philosophy on the Ethiopian soil must underscore the contributions of the Canadian philosopher Claude Sumner to Ethiopian philosophy. Sumner introduced a large philosophical scheme which managed to analyze the indigenous, traditional, oral, written and modern philosophical approaches on the Ethiopian soil. Sumner studied indigenous, oral wisdoms reflecting on societal values, critical philosophical adaptations into the Ethiopian soil as well as original philosophical works. Sumner, "assessing the contributions of Ethiopian philosophers, he contends that these modalities of philosophizing are of two kinds. The broadly philosophical are also unoriginal but adoptive and creatively incorporative. The strictly philosophical are distinctly original" (Teodros, 1996, p. 41)

Sumner understood the essence of philosophizing loosely and in a narrower sense. Generally whereas philosophy refers to how societies explain their place in the emblem of existence, particularly philosophy also refers to a critical and rigorous exercise made possible by the power of rationality. Within the Ethiopian context, Sumner believed that "the oral literature of the Oromos, very much like traditions of Akan and Yoruba, is a philosophy with sophisticated conceptual frames and highly refined philosophies of the person"( Kiros, 1996, p. 40). Arguing that classical Ethiopian philosophy is comprised out of creative adaptations that sought to appropriate ancient wisdom form Greek, Arab and other 
cultures to the Ethiopian context, Sumner believed that such forms of adaptation also form one integral component of Ethiopian philosophy.

Sumner located the strict form of philosophizing in Ethiopian philosophy in the original works of Zera Yaocb and Wolde Hiwot. Although he dwelled largely on the existence of Ethiopian philosophy, Sumner's conception of philosophy is oriented towards objectivist aspirations in that, rather than situating one culture as the ultimate source of philosophy, he sought to demonstrate the existence of analogous structural patterns across boundaries. As such, "Sumner himself expressed his disinterest in tracing philosophy's roots from one country to another in his theory of parallelism of proverbs" (Presbey and Mclean, 2013, p. ix). Supporting such nature of philosophy that witnesses a dialectical relation between the universal and particular sites of knowledge, Ram Adhar Mall argues, philosophical efforts are not just abstract concepts devoid of particularities, but culturally oriented realizations, resituating the universal within the particular. Here, trying to prioritize one culture over the other in the name of pure universality neglects the contextual aspects of all human knowledge. Alongside these lines "there is almost no philosophy that can claim to be fully free from influence" (Mall, 2000, p. 1).

\section{Sumner on the Classical Foundations of Ethiopian Philosophy}

Mudimbe believes that there are unique features of Ethiopian philosophy as discussed in the works of Claude Sumner. Instead of being located in Africa's precolonial past, the critical adaptation of foreign philosophies into the Ethiopian soil, study of oral wisdom and original philosophical treatise form the main corpus of Ethiopian philosophy. Particularly, the philosophical investigations of Zera Yacob and Wolde Hiwot show the value of local contexts of knowledge and space in philosophical pursuits. As such, "one cannot ignore that some of them, such as the books of Zar'a Yacob and Walda Heywat, witness to a regional inspiration" (Mudimbe, 1988, p. 203).

Sumner begins his studies of Ethiopian philosophy with the assumption that a better understanding of Ethiopian philosophy could be made possible through an analysis of the terms "Ethiopia" and "philosophy". What first complicates such an effort is the fact that different connotations of modern Ethiopia could be proposed based on spatio-temporal location, language and "religiously, between the Christians, the Moslems, and the Jewish Falashas"(Sumner, 1996, 1). Regarding the nature of Ethiopian philosophy, questions like what are the different sources and modalities of Ethiopian philosophy, Is Ethiopian philosophy entirely original or an attempt to introduce alien ideals into the Ethiopian soil, and what is the place of philosophy in 
Ethiopian society, need to be closely considered. Sumner asks, Is Ethiopian philosophy, "a popular traditional wisdom or a critical examination; an original inquiry indigenous to the country or a literature of translation and adaptation" (Mudimbe, 1988, p. 2)?

Sumner witnesses an element of dialectics in the evolution of Ethiopian philosophy. Here he draws a parallel between the introduction of Greek philosophy into the rest of Europe and the way in which Greek philosophy is transferred in the Ethiopian soil. It is a gradual mutation and adaptation, an attempt to indigenize such philosophical ideals and a creative process of translation that characterizes such a process of introducing ancient Greek philosophy to the other parts of the world. In the Ethiopian context such process of adaptation characterizes "The Book of the Philosophers and The Life and Maxims of Skendes" (Mudimbe, 1988, p. 6).

For Sumner, the Ethiopic or Ge'ez version of The Book of the Wise Philosophers was translated from an Arabic version which is in return made available from the Greek original version. Although, not original, the way in which the text is adapted to the Ethiopian context and the effort to replace Greek names with Ethiopian equivalents put discourses into Ethiopian literary forms of translation shows that it is a text valuable enough to the study of philosophy in Ethiopia ${ }^{2}$. Speaking of the text, Sumner maintains "the Ethiopic text was translated bä'afä Mikael, "by the mouth of Mikael:" the author orally rendered an Arabic text into current language and an Ethiopian wrote it in Ethiopic on parchment" (Sumner, 1974, p. 21).

The Book of the Wise Philosophers employs a unique method of synthesis that mediates foreign philosophical wisdom with indigenous realities. Such method of translation and introduction of foreign works into the Ethiopian soil is not just new to this book but characterizes the analysis and translation of other texts like The Life and Maxims of Skendes. The primary significance of classic works like The Book of the Wise Philosophers and The Life and Maxims of Skendes resides in their moral teachings and ethical standards that they purport to introduce. Particularly The Book of the Wise Philosophers "presents the quintessence of what various "philosophers" have said on a certain number of topics, the greater number of which are ethical" (Sumner, 1974, p. 24-25).

\footnotetext{
${ }^{2}$ A discussion of the unique Ethiopian tradition of translating foreign texts is found in Donald Levine's Greater Ethiopia.
} 


\section{The Hatetas and the Written Sources of Ethiopian Philosophy}

Particularly belonging to the written Ethiopian philosophical traditions, Zera Yacob's hateta constituted a philosophical biography and methodology that sought a rational analysis for religious disputes through a rational model, having implications for social and political philosophy and serving as a model of religious pluralism. I think Sumner primarily raises philosophical questions pertaining to metaphysics, epistemology and ethics. The background to Zera Yacob's philosophy is characterized by the influence of the teachings of the Christian religion. Still, rather than simply inheriting the Christian faith and its teachings, Zera Yacob rationally reflected on the Essence of God, nature of evil, meaning of life and issues in moral, social and political life. Reflecting on the origins of the hateta, Sumner argues "It is precisely this intimate link with Christianity in general and monasticism in particular that Zera Yacob breaks away with, although his thought remains deeply theistic" (Sumner, 1996, p. 7)

The form of expression and linguistic ideals employed by Zera Yacob for Sumner are inherited from the language of the Ethiopian Orthodox Church. Appropriating the analytic tools of traditional church education in Ethiopia, Zera Yacob introduced a rigorous and analytic philosophical method known as the hateta. As Sumner sees it, "the prose of Zera Yacob reflects the language that is taught in the qene school; it is the jewel, the masterpiece of Ethiopian literature" (Sumner, 2004, p. 173). While most of the corpus of Ethiopian philosophy belongs to the stock of either oral tradition or foreign wisdom appropriated to the Ethiopian soil, the work of Zera Yacob is unique in being a unique autobiography that recounts the journey of an individual in a world of religious conflict and the quest for meaning through a philosophical exercise. Sumner firmly believes that, "Zera Yacob's philosophy is an absolutely original work, the fruit of his own personal reflection and not a translation or an adaptation from foreign sources, as most Ethiopic literature is" (Sumner, 2004, p. 174).

Being developed in terms of an autobiography, Zera Yacob's philosophical work the hateta deals with diverse topics. It starts off by recounting the story of Zera Yacob, his background in religious teaching, his quarrels with members of different faiths and subsequently being forced into exile. Once Zera Yacob situates his philosophical origins, he goes on to discuss the nature of knowledge and everyday opinion, the problem of theodicy, examine the doctrines of different religions and investigates the role of prayer and the human heart in the understanding of ultimate reality. Finally, Zera Yacob discusses how he eventually produced his philosophical treatise being motivated by one of his disciples. 
Zera Yacob in the hateta relates his background to the influence of both indigenous as well as foreign religious teachings. He claims, "I learned the interpretations both of the Frang and of our own scholars" (Sumner, 1976, p. 4) His philosophy was therefore affected by the introduction of Catholicism in Ethiopia during the reign of Susenyos and the resulting religious disputes and conflicts. This is because Zara Yacob was said to have been compositing a philosophical text partly in response to the Catholics. In the Hateta Zera Yacob asks, all proclaim to have the truth, but truth is one, so how could one discover the nature of ultimate truth. He assumes, "the Frang say this and this" or "the Copts say that and that", and I did not say "This is good, that is bad" (Sumner, 1976, p. 5). Such investigation leads him into being charged with heresy and challenging the power and authority of the king. Fearing persecution Zera Yacob fled, retreated into a cave and begun to contemplate the nature of truth and human nature.

Sumner believes that the awe and admiration given to Zera Yacob's hateta was not extended to the work of his disciple Wolde Hiwot. Whereas the position of the hateta in the world of knowledge production and decolonization efforts in Africa, were beginning to be explored, no attention has been given to another major philosophical contribution found in the work of Walda Heywat. Sumner contends, "When at long last, after three centuries of quasi-oblivion, it became aware of the great light that was Zera Yacob the Philosopher, it left in the dark his disciple Walda Heywat. And when the continent of Africa, nay the world at large, discovered in Zera Yacob a rationalist, a free thinker, the glow of an enlightenment in the shadows of the African past, it opened its arms to the original master, and left the disciple amidst the embers of the night" (Sumner, 2004, p. 172). Comparing the ideas of Wolde Hiwot's to his master, Sumner believes that although Wolde Hiwot's philosophy was founded on and heavily drew on the ideas of Zera Yacob, he believes that the two thinkings were still different in a number of ways. First of all, Wolde Hiwot employs his own forms of delivery that differ from the autobiographical method introduced by his master. Secondly, "Walda Heywat is remarkable for his pedagogical qualities" (Sumner, 2004, p. 175)

Getachew Haile believes that although Claude Sumner exerted an immense effort in trying to show the originality of the hateta, still not many were sympathetic to such endeavors. This arose from the fact that, Zera Yacob was highly critical towards the practices of Orthodox Christian Church. Because of this, some saw Zera Yacob as despising the teachings of the Orthodox Church as well as degrading the achievements of Christian rulers like Fasilades. (Getachew, 2006, p. 10). Getachew personally doubts the authenticity of Zera Yacob's hateta due to two reasons. First of all, he believes that the way in which Zera Yacob 
deduced the existence of God shows the influence of Catholicism in his thoughts. This constitutes an approach of natural theology which is founded on the usage of facts of observation in order to prove the existence of God. Secondly, the hateta's explorations towards the nature of the stars and how far they are from the earth shows the influence of Catholicism as well. What matters most for Getachew is not whether the hateta belonged to an Ethiopian - an issue that has been of great concern for some writers, including the author of this article ${ }^{3}$. Getachew believes that Zera Yacob was an Ethiopian who was willing to learn from the teachings of different cultures and religions and presented such a synthesis with his unique form of writing and expression. The Catholic medieval theologian and philosopher Thomas Aquinas also used such an approach through the introduction of the five arguments for the existence of God in his work Summa Theologica.

\section{Oral Wisdom as an Aspect of Ethiopian Philosophy}

For Claude Sumner, the different modalities of expression and philosophical productions must be included in the attempt to study the nature of Ethiopian philosophy. He observes that most attempts to study Ethiopian philosophy concentrate on the original works of philosophy that use a written form of expression. Against such a narrow focus he remarks, "no study on Ethiopian thought could be complete if it limited itself to its written formulation" (Sumner, 1999, p. 11). There are different forms of societal solidarity that provide the common moral fabric and sense of a common identity. One of such platforms of a common origin is an oral tradition. Oral tradition creates a space for a direct interaction among the members of a community. It is a way of addressing existing predicaments, inculcating moral values and transferring societal wisdom from one generation to the other. Comparing written and oral forms of philosophical expression, Sumner argues, "whereas the author of a written text entrusts his work to the public, ignoring what acceptance or rebuff he may receive from his readers, the sender and the receiver in oral communication must be present at the same time" (Sumner, 1999, p. 12).

For the success of an oral form of communication, individuals must share a common reference and worldview and physical proximity. This shows that, "a cultural unity must exist between the speakers; they share the same language, the same semantics, the same images, and the same values" (Sumner, 1999, p. 14). Sumner observes that in Oromo proverbs, there is a primary goal of transferring

\footnotetext{
${ }^{3}$ See the article included in this issue (Fasil and Setargew, pp.61-76).
} 
moral insights and teachings. The proverbs are phrased as moral rules that ought to be followed by all members of a community. The proverbs are largely expressed in "the negative: "Do not do such an action!" (Sumner, 1999, p. 15). Sumner believes that there are many teachings in Oromo wisdom that show the presence of a holistic view of the universe. He argues, "if the latter is "anthropocentric" and "personalized," the former is "ecological" (Sumner, 1999, p. 22). The background for Oromo wisdom and oral literature is found in the natural setting of the community, closeness with nature and an agrarian and communal way of life. Perhaps Sumner didn't realize that such oral wisdom pervades the rest of the country, including where the written literary tradition thrived. The oral wisdom is broader encompassing both views on reality and the place of man in the universe as well as the nature of everyday societal affairs. Generally proverbs and oral wisdom are significant for the development of philosophical knowledge in a number of ways. Sumner here contends, "the proverb has many functions: (1) cognitive, (2) expressive, (3) normative and educative, (4) discursive, and (5) cultural: (Sumner, 1999, p. 27).

\section{Sumner and the Vitality of an Ethiopian Philosophy}

As said, the major contribution of Claude Sumner to the field of African philosophy lies in paving the way for a new reconstructive project that challenged Eurocentric bias that saw Africa as the land devoid of the culture of philosophy and the refined aspects of human civilization. Sumner throughout his studies introduced a research project that sought to unearth Ethiopia's written, unwritten and creatively appropriated sources of philosophy. To this extent, he "debunked the stereotypes of Africa as a land without a history of written philosophical texts" (Presbey and Mclean, 2013, p. viii). In his analysis of the existence and dimensions of Ethiopian philosophy, Sumner didn't saw the category of race as a major factor in the evolution of Ethiopian philosophy. This creates a suitable platform for explaining the interaction among different philosophical systems and their interaction with forces of history. This is founded on his idea that "race is both an unclear and an unimportant category in Ethiopia" (Presbey and Mclean, 2013, p. ix).

The greatest contribution of Claude Sumner is as such found in proving the existence of African philosophy through his studies on Ethiopian philosophy. Such study identified oral, written and adaptive elements in Ethiopian philosophy. Adding to the effort to identify the different aspects of African philosophy, Sumner "adds a new dimension by championing a collection of written texts from medieval and early modern Ethiopia" (Presbey, 2003, p. 422). Besides studying original 
contributions and individual texts in his study of Ethiopian philosophy, Sumner also devotes his attention to texts of a foreign origin that have an intention of imparting moral wisdom.

Although Sumner conceived traditional texts in Ethiopia as components of African philosophy, some are skeptical calling such texts as a form of ethnophilosophy and ways of degrading the mentality of Africans. As Presbey sees it, "While acknowledging the impact the sapiential tradition has had in Ethiopia, some of Sumner's African colleagues have had reservations about its value" (Presbey, 2003, p. 423). Sumner escapes such charges since he didn't limit the existence of Ethiopian philosophy to Ethiopia's past indigenous wisdom and knowledge systems. He also didn't employ his different findings on Ethiopian philosophy in order to generalize on the thought patterns and systems of knowledge of Ethiopians as such. Above anything else Sumner emphasized dialectical relations among philosophical traditions, interaction with societal forces and different manifestations of philosophical culture.

Beside such monumental contributions, for Presbey what is missing in Sumner's philosophical explorations is a holistic investigation that understands the influence of Ethiopian philosophical texts to social, political and other walks of life. As such, "While Sumner excels in certain forms of analysis of texts; he has not focused on whether the wisdom put forward in the texts has a relationship to political and social power" (Presbey, 2003, p. 424). There is a need to introduce a research project that situates the role of Ethiopian philosophy for contemporary Ethiopian society. This could be accomplished through studying the cultural milieu and existential forces that animate philosophical thinking in Ethiopia as such.

Maimire Mennasemay contends that, one needs to situate the significance of Claude Sumner's contribution to Ethiopian philosophy in light of the cultural differences he witnessed among Ethiopian and western ways of living. Recognizing such a huge cultural difference, he devoted himself to identifying the different modalities in which Ethiopian philosophy is expressed. Maimire believes that we need to recognize that, "the Ethiopian cultural milieu in which Sumner was working was radically different from that of his origin" (Maimire, 2012, p. 201). In Sumner's studies of Ethiopian philosophy one witnesses the attempt to situate the role of Ethiopian philosophy in comparison with both western philosophy as well as the debate on African philosophy. He as such sought to compare among other Zera Yacob's philosophy with that of Kant and Descartes, and also demonstrated how Ethiopian philosophy presents a unique dimension in African philosophy. Such uniqueness arises from having written philosophy, combined with oral and adaptive elements. Furthermore, Sumner "inspired his students to reflect seriously 
on the place of philosophical thinking in Ethiopian culture" (Maimire, 2012, p. 202).

Teodros Kiros on his part believes that Sumner's inputs to philosophy could be seen from two angles, universal and local. Universally Sumner was interested in exploring the prospects of modernity driven by reason and rationality. He sought to explore different philosophical tools developed by thinkers across different boundaries, in the march of modernity towards freedom and emancipation. Just like the struggle against tradition and authority initialed by philosophers like Descartes, "in the mountains of Ethiopia, Zera Yacob was busily sharpening his radical method of the hatetas, with which he was methodically dismantling, layer by layer, piece by piece, the dominant prejudices of backward Ethiopia, specifically its religious practices and old custom." (Kiros, 1996, p. 50). Locally, Sumner was heavily engaged in the field of Ethiopian philosophy, diverse forms of philosophical expression and the place of Ethiopian philosophy in Ethiopian culture and civilization. Sumner's Ethiopian philosophy as such contributes to the philosophical discussion on Ethiopian modernity. While it seems short in systematically situating Ethiopian philosophy in the real life stuations, politics and social dilemmas, Sumner still laid the foundations for contemporary Ethiopian philosophy.

Teodros Kiros conceives the role of philosophy in being a critical and moral practice. Philosophy must examine the existential predicaments in human life and must propose possibilities that are ethically sound. Our moral ideals must strive to create a world where love and self-sacrifice are key virtues rather than seeing others as a means to an end. Teodros argues that we must be "willing to give without receiving, or is willing to give without the deliberate intent of receiving anything, or for which the receiving is only incidental. The generous person gives a particular good A to person $\mathrm{B}$; and person $\mathrm{B}$ does not simply receive $\mathrm{A}$ as a matter of course. $\mathrm{B}$ receives $\mathrm{A}$ with a profound respect for the giver, and even plans, if she can, to one day reciprocate not in the same way, but in some way" (Teodros, 2013, p. 205). Such a quest for a critical and moral practice could be founded in the ancient Egyptian moral ideal of Maat for Teodros. Such a vision encompasses respect for what is alien and having intrinsic motive towards others. Accordingly, "the purity is measured by the quality and quantity of the compassion that is extended to any needy human being, uncontaminated by external motives, such as love, friendship, acquaintance and relation"( Teodros, 2013, p. 207).

In a context in which African philosophy was equated with communal wisdom and group thinking, Sumner initiated a philosophical approach that identified different forms of philosophical thought in Ethiopia. Such a project 
broadly encompasses a written tradition, foreign philosophical wisdom that is creatively adapted and oral wisdom that is passed down from one generation into the other. Such an undertaking proves useful in two dominant ways. First of all, it introduced the field of Ethiopian philosophy to the world of knowledge production. Secondly, it defied the Eurocentric bias which alleges that non-western societies do not have rational forms of expression to introduce a philosophical culture that appears in terms of different modalities.

\section{Conclusion}

Claude Sumner succeeded in introducing a philosophical edifice through which the different modalities of Ethiopian philosophy could easily find an expression. Unearthing the written, oral and adopted sources of Ethiopian philosophy, Sumner called on the need to demonstrate the role of philosophy in Ethiopian public life and matters of existing needs. Sumner's philosophical investigations were informed by two basic goals. The first one is the need to demonstrate the existence of a philosophical tradition in different non-Western parts of the world which is comparable in stature to the Western tradition. Secondly, Sumner sought to show that philosophy rather than being seen as an ivory tower needs to demonstrate its role in everyday human affairs. This means that philosophical categories must be practically applied in order to analyze existential predicaments and existing human problems. To such a degree the real value of philosophy resides not just in being immersed in theoretical debates but in solving everyday problems.

Sumner escapes the charge of ethnophilosophy in African philosophy. Being grounded on the analysis of Bantu philosophy as a collective worldview, such criticism alleges that African philosophy must be practiced at the level of an individual in a rigorous manner. The criticism of ethnophilosophy charges different systems of thought in Africa as being complacent in relations of ideological manipulating and perpetuating colonial bias. But Sumner's philosophy was motivated by the desire to explore different kinds of philosophical wisdom of the world without subjugating them to the spirit of hierarchical gradation. 


\section{References}

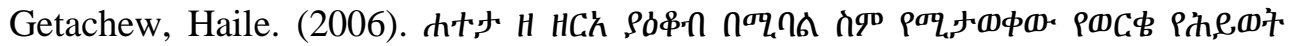
Fth (Hateta zerayacob bemibal sim yemitawekew yewerke yehiwot tarik) Collegeville, Minnesota.

Mall, Ram Adhar. (2000). Intercultural Philosophy. Boston: Rowman and Littlefield publishers.

Masolo, D. A. (2003). Philosophy and indigenous knowledge: An African perspective. Africa today, 50(2), 21-38.

Medina, V. (1992). The possibility of an indigenous philosophy: A Latin American perspective, American Philosophical Quarterly, 29(4), 73-380.

Mennasemay, Maimire. (2012). Claude Sumner, S.J. (1919-2012). International Journal of Ethiopian Studies, 6 (1/2), 200-202.

Mudimbe, V. Y. (1988). The Invention of Africa: Gnosis, Philosophy, and the Order of Knowledge. Bloomington: Indiana University Press.

Presbey, G., M. (2003). Should women love 'wisdom'? In P.H Coetzee \& A.P.J Roux (Eds.), The African Philosophy Reader (pp. 422-435). London: Routledge.

Presbey, G., M. and Mclean, G., F. (2013). In Memory: The significance of Claude Sumner S. J's contribution to African philosophy in Gutema, Bekele and Verharen, Charles C. (Eds.), African Philosophy in Ethiopia: Ethiopian Philosophical Studies II, The Council for Research in Values and Philosophy. Washington, D.C.: The Council for Research in Values and Philosophy.

Sumner, C. (1974). Ethiopian Philosophy, Vol. I: The Book of the Wise Philosophers, Commercial Printing Press.

Sumner, C. 1976. The Treatise of Zara Yacob and of Welda Heywat, Text and Authorship. Addis Ababa: Commercial Printing Press.

Sumner, Claude. (1996 December). The significance of Ethiopian Philosophy for the problematics of an African Philosophy. Paper prepared for the Pan-African Symposium "Problematics of an African Philosophy Twenty Years After (1976-1996)", Addis Ababa.

Sumner, C. (1999). The proverb and oral society. New Political Science, 21(1), 1131.

Sumner, C. (2004). The Light and the Shadow: Zera Yacob and Walda Heywat: Two Ethiopian Philosophers of the Seventeenth Century, in Wiredu, Kwasi. A Companion to African Philosophy Blackwell Publishing Ltd, Malden, USA. 
Fasil Merawi

Teodros Kiros, (1996). Claude Sumner's classical Ethiopian philosophy. Northeast African Studies, New Series, 3(2), 39-52.

Teodros Kiros, (2013). Moral economy: An original economic form for the African condition, pp 203-211, in Bekele, Gutema and Charles, C. Verharen (Eds.), African philosophy in Ethiopia: Ethiopian philosophical studies II(pp. 203-211). Washington, D.C.: The Council for Research in Values and Philosophy. 